\title{
Impressões Pessoais do Dr. Wilson Barbosa Martins a respeito da política no sul de
Mato Grosso entre as décadas de 1930 e 1960
}

Bruno Torquato Silva Ferreira* Marcos Hanemann ${ }^{* *}$

O político e advogado Wilson Barbosa Martins nasceu em Campo Grande no dia 21 de junho de 1917. É filho de Henrique e Adelaide e irmão de Plínio Barbosa Martins (1926-1998), também político de destaque. Foi casado durante sessenta anos com Nelly Martins (1923-2003), filha de Vespasiano Martins, seu tio. Acordou para a política com a Revolução Constitucionalista de 1932, quando tinha 15 anos de idade e, desde então, passou a tomar parte ativamente na vida pública do sul do estado de Mato Grosso, posteriormente Mato Grosso do Sul, tendo ocupado diversos cargos: prefeito de Campo Grande (19591963), duas vezes deputado federal por Mato Grosso (1963-1967/1967-1971), duas vezes governador de Mato Grosso do Sul (1983-1986/1995-1999), sendo seu primeiro governador eleito, e senador por Mato Grosso do Sul (19871994). Além disso, desde os anos 1930, destacou-se como grande defensor da "causa divisionista" do sul de Mato Grosso.

Recebidos pelo Dr. Wilson Barbosa Martins em seu escritório particular no dia 4 de abril de 2004, explicamos que tencionávamos fazer uma pesquisa a

\footnotetext{
* Mestre em História pelo Programa de Pós-Graduação em História da Universidade Federal da Grande Dourados (UFGD) e doutorando em História pela Universidade Federal do Paraná (UFPR)

** Doutorando do Programa de Pós-Graduação em História Social da Universidade de São Paulo (USP).
} 
respeito do Movimento Constitucionalista de 1932, principalmente, e conhecer também aspectos da vida e atuação política do Dr. Vespasiano Martins. Nós, Bruno Torquato Silva Ferreira e Marcos Hanemann, então estudantes do curso de História da Universidade Federal de Mato Grosso do Sul (CCHS/Campo Grande), começamos a fazer as perguntas:

Marcos Hanemann - O movimento de 32 faz parte de uma corrente de movimentos divisionistas que houve aqui no estado. Havia esse ideal no sul do estado...

Wilson Barbosa Martins - Ele [Vespasiano Martins] era o líder dessa corrente divisionista.

MH - Por que essa vontade? O que tinha o norte do estado que atrapalhava o sul do estado?

WBM - O que ocorreu foi que Campo Grande crescendo, especialmente a partir da vinda da estrada de ferro, em 1914, para Mato Grosso do Sul, chegando até Porto Esperança inicialmente, mais tarde até Corumbá, Campo Grande se transforma num centro comercial por excelência, o grande pólo de desenvolvimento econômico do estado. Cada vez mais passou a ser um centro de serviços, ensino, de saúde, não é?

MH - Os profissionais liberais todos...

WBM - É. Então, Campo Grande ansiava já muito cedo por essa divisão, porque naquela época não havia estradas para Cuiabá. A estrada para Cuiabá surgiu propriamente na administração do Dr. Arnaldo Figueiredo. As comunicações eram difíceis e a distância muito grande, a nossa participação na receita estadual cada vez maior, com o crescimento da cidade e nós não recebíamos em troca as verbas necessárias... Nós não recebíamos os recursos necessários para empurrar o crescimento e cada vez mais, aquela idéia surgida no passado, há mais de cem anos, se tornava aguda, imperiosa, a idéia de fazer a divisão que acabou se tornando evidente na Revolução de 32, quando São Paulo, cobrando do ditador Vargas, uma Constituição, foi inclusive às armas fazer uma Revolução. São Paulo ficou isolado, embora tivesse inicialmente promessas daqui e dali, de alianças do Rio Grande, de Minas, na verdade só quem não lhe faltou foi o sul de Mato Grosso através dessa corrente divisionista. 
MH - Depois dessa tomada em armas de São Paulo, algumas fontes dizem que, como retaliação do Governo Federal, foram criados os territórios de Ponta Porã e Rondônia pra diminuir a receita do estado. O senhor acha que essa informação procede porque, já que o sul do estado que se rebelou, por que tirar as receitas de Cuiabá, que apoiou o governo Vargas?

WBM - A formação do Território não me parece que tenha vindo como um ato de retaliação. Parece que era um desejo de formação de núcleos de fronteiras, de desenvolvimento de regiões próximas à fronteira da Bolívia e do Paraguai. Só que o Território de Ponta Porã não englobou toda área que desejava emancipar-se de Mato Grosso e mostrou-se assim uma reformulação geográfica de menor importância e acabou fracassando; teve que ser extinto o Território de Ponta Porã.

MH - Nesse movimento revolucionário de 32 foram publicados alguns Diários Oficiais aqui. Esses diários oficiais falam no Mato Grosso revolucionário e as fontes que falam a respeito desse movimento falam da criação do estado de Maracaju. Por que que há esse descompasso, pois o Dr. Vespasiano assinou os diários oficiais intitulado como governador de Mato Grosso? O que aconteceu naquele momento: as pessoas chamavam esse estado de Maracaju, ou não chamavam?

WBM - O nome oficial do estado era estado de Mato Grosso. A Revolução veio e o movimento do sul de Mato Grosso continuou oficialmente chamando o estado de Mato Grosso. Apenas como estado revolucionário, que passou a ter sede em Campo Grande. Então Maracaju é um nome como outros que estavam para ser examinados para ver se correspondiam à vontade da maioria para ser o nome daquele território. Posteriormente, quando foi feita a própria divisão, em 77, o Geisel (que foi o presidente que editou a lei, que fez o desmembramento de Mato Grosso em Mato Grosso do Sul e Mato Grosso), o Geisel pretendia que se desse o nome de Campo Grande ao Mato Grosso do Sul, mas as pessoas presentes não aceitaram o nome de Campo Grande porque achavam que isso magoaria a maioria dos municípios; daria uma primazia a Campo Grande. Primeiro por ser capital, depois também com o nome de Estado de Campo Grande, então não aceitaram. Os políticos presentes não sancionaram. E assim ficou Mato Grosso do Sul e o outro pedaço maior, quase $2 / 3$ do nosso território antigo ficaram com a denominação anterior de Mato Grosso, não ficou Mato Grosso do Norte. 
MH - Qual foi a participação dos militares nesse processo de tomada em armas. Eles chegaram a impor esse cargo de governador revolucionário, de governador de Mato Grosso ao Dr. Vespasiano? Como foi a aceitação do Dr. Vespasiano a esse cargo?

WBM - Vespasiano, na ocasião era o líder inconteste do sul, era a figura de maior expressão política. Um grande médico e tinha uma grande soma de lideranças políticas. Então era fácil chegar-se ao Vespasiano, com essa soma de personalidades de prestígio, chegar a ele como uma unanimidade. Além disso, ele era amigo pessoal do Comandante da Circunscrição Militar de Mato Grosso, que era o Klinger, chefe das forças revolucinárias. O Klinger aliciou o Vespasiano, pediu que ele assumisse o cargo. Ele então assumiu por isso, porque o chefe do movimento veio a ele e convocou-o para que assumisse. Vespasiano não teve como fugir daquele encargo.

MH - Naquele momento, já que ele estava como governador desse estado revolucionário, por que ele não propôs ao gen. Klinger que apenas o sul do estado se tornasse revolucionário e usasse esse movimento como um movimento divisionista? Não seria melhor deixar Cuiabá com os interventores de Getúlio?

WBM - Naquele instante, o movimento estava se formando, detonou aqui o movimento e, como sempre acontece nos movimentos sociais, você não tem uma medida exata das suas proporções, você só vai conhecendo exatamente nos seus desdobramentos. Você não sabe que cidades vão ficar com o movimento, que cidades vão ficar contra. Então, o que ambas as partes pretendiam era que fossem envolvidas as demais: o norte pretendia envolver o sul e o sul pretendia envolver os municípios em maior número.

Bruno Torquato Silva Ferreira - O que a gente percebe no Movimento Constitucionalista é a aliança das lideranças civis de Campo Grande com os militares da Circunscrição Militar. Essa aliança se dá desde o começo, com a instalação das unidades federais? Essa igualdade de propostas...

WBM - Havia sempre muito bom relacionamento entre os militares e as lideranças políticas de Campo Grande. Porque as lideranças políticas de Campo Grande estavam atentas ao problema da sede dos militares no estado. Nós tínhamos uma circunscrição militar em Corumbá e o Calógeras, Ministro da Guerra, quando andou por aqui, ele acertou com as lideranças de Campo Grande que traria que 
traria para cá a sede da Circunscrição Militar. E efetivamente a circunscrição Militar veio para Campo Grande. Não foi para Cuiabá. Isso fortaleceu muito Campo Grande.

BT - Campo Grande se fortaleceu politicamente frente, principalmente, a Corumbá e Nioaque...

WBM - Fortaleceu muito ao sul todo e, em conseqüência, Campo Grande aparecia como a liderança do sul pra enfrentar o norte.

BT - O Movimento Tenentista teve repercussão nacional. O senhor vivenciou um pouco esse momento, poderia dizer quais os desdobramentos dele em Campo Grande antes de 32?

WBM - O Movimento Tenentista era um movimento que desejava uma mudança no Brasil já a partir de 22. A primeira manifestação tenentista no Brasil foi o Levante do Forte de Copacabana, ali é que surgiu a oficialidade que veio para a rua, depois de ver fracassado um movimento que eles tinham articulado, num levante contra o governo, veio pra rua e queria ir pro palácio pra depor o Presidente da República. Estavam os 13 do Forte; ficaram o Eduardo Gomes e mais um, que não me vem à memória agora... Inclusive um civil que aderiu aos militares que ele viu marchando pela praia. Foi a primeira manifestação dos tenentes contra a situação existente no país. Eles queriam a modificação da legislação, especialmente a legislação eleitoral; achavam que as eleições se faziam fraudulentamente, as eleições chamadas "à bico de pena", quando ainda não havia o voto secreto e nem era dado o direito de voto às mulheres. $\mathrm{O}$ movimento seguinte foi em 24, movimento que ficou mais circunscrito a São Paulo: Levante do Isidoro Dias Lopes e do Miguel Costa - os dois chefes principais do movimento. Veio uma pequena manifestação em 26 , depois veio a de 30 , que coroou todas as demais, em que levantou-se o estado do Rio Grande do Sul, articulado com outros, e acabaram vencendo a Revolução de 30, com a chefia do Getúlio, do Góes Monteiro... Góes Monteiro foi o chefe da Revolução, vencendo em três meses os adversários e acabaram depondo o Presidente da República, que era Washington Luís, e o Presidente eleito, que era o Júlio Prestes, governador de São Paulo. Foi nomeada uma junta governativa, e assim se coroou num movimento vitorioso os ideais da Revolução de 30. E esses ideais deles [os tententes] foram expressos na legislação que veio a partir da posse do Getúlio. 
BT - O Dr. Vespasiano apoiou a Revolução de 30?

WBM - Eu não me lembro, não sei. Eu não saberia dizer porque em $30 \mathrm{eu}$ era um menino de treze anos e não sabia nada a respeito da vida pública, só fui acordar pra situação brasileira em 32, já com quinze anos, quando eu estava matriculado no ginásio, aqui em Campo Grande, e vi o Dr. Vespasiano, então, ser elevado à posição de governador.

MH - Pensando que o Movimento Tenentista tinha ideais, vamos dizer assim, nobres, e que levado ao poder, Getúlio Vargas acabou se tornando um ditador, o que teria degenerado esse movimento?

WBM - Os ideais de 30 foram corporificados nele como chefe de governo. Ele inicialmente recebeu [o poder] de uma junta governativa, da qual fazia parte, entre outros, o Tasso Fragoso. A Constituição da República Velha foi derrogada com a Revolução e São Paulo queria que ele convocasse uma Constituinte que aprovasse uma Constituição para o país. Por isso a Revolução de 32, da qual já tratamos rapidamente. Getúlio em 34 convocou uma Constituinte e veio uma Constituição em 34. Posteriormente, o Getúlio, em 37 - depois de um início de Revolução Comunista, em 35, e de uma Revolução Integralista, em 36, esta comandada por Plínio Salgado, aquela comandada por Luis Carlos Prestes - o Getúlio decretou o Estado Novo e outorgou ao país uma Constituição, derrogando a Constituição de 34, nitidamente ditatorial, em que o Poder Executivo enfeixava os Poderes do Legislativo e do Judiciário, então ficou uma situação muito difícil para o país. Getúlio passou a governar o país ditatorialmente. Isso foi até 45, quando o Getúlio foi deposto do governo, mas não foi exilado: ele foi pra fazenda dele, em Itu, e lá ficou. Foi feita uma eleição logo em 46, um ano depois, e foi eleito Presidente da República Eurico Gaspar Dutra com apoio de Getúlio, e ele, Getúlio, se fez candidato ao Parlamento. De acordo com a legislação eleitoral de então, ele pôde ser candidato em vários estados, se elegeu por vários estados, mas acabou tomando posse como Senador pelo Distrito Federal, onde teve uma votação esmagadora.

BT - Dizem que os tenentes de 22 foram os generais de 64: Geisel, Castelo Branco, todos esses eram tenentes naquela época...

WBM - Em 45, quem tomou o poder foram as Forças Armadas, mas voltou o Getúlio. Em 54 veio o golpe novamente das Forças Armadas, mas daí pra alijar 
de vez o Vargas. Ele foi deposto pelas Forças Armadas naquele episódio da rua Toneleiros, quando um dos asseclas do Palácio do Catete, comandado de Gregório, que era segurança do Getúlio, chamado Climério, atirou no Lacerda quando ele ia descer em casa... Tinha vindo de uma reunião com o Maj. Rubem Florentino Vaz, e [Climério] baleou o Lacerda no pé e matou o Rubem Florentino Vaz, que era amigo do Lacerda. As Forças Armadas se fecharam e depuseram o Vargas; houve uma reunião no Catete, da qual participaram todos os Ministros; Tancredo era Ministro da Justiça, Zenóbio da Costa era Ministro da Guerra, participou também a filha do Getúlio, a Alzira Vargas do Amaral Peixoto. Getúlio tinha colocado como chefe de polícia do Distrito Federal - que era o Rio de Janeiro - tinha posto o irmão dele, Benjamim Vargas, Bejo Vargas. Isso irritou profundamente os políticos. O Getúlio não queria renunciar, como desejavam as Forças Armadas... que ele saísse do poder. E ele queria encontrar uma fórmula pra sair com honra do poder e permitiram a ele uma licença, de discutir uma licença, um licenciamento, mas às quatro horas da manhã, depois de discutirem muito, ele e os ministros, e não terem chegado a um acordo, sobre se ele renunciava ou se ele não renunciava, ele foi pros aposentos dele e nas primeiras horas da manhã se suicidou com uma bala no peito. Assim se encerrou o ciclo Getúlio, que governou de 30 a 45, 15 anos; e de 50, quando se tornou Presidente pelo voto popular - uma votação imensa - a 54, mais quatro anos. Então, ele governou dezenove anos.

MH - Nesse período, qual era a posição do Dr. Vespasiano aqui no estado? O que Vespasiano pensava? Ele teve uma atuação política durante o Estado Novo?

WBM - Naquele tempo não havia eleições. Os prefeitos eram nomeados pelos interventores.

BT - O Dr. Vespasiano foi exilado depois de 32? Quanto tempo ele passou no exílio?

WBM - Ficou alguns meses no exílio. Em Ponta Porã... no Paraguai. Não Ponta Porã, em Pero Juan Caballero, alugou casa lá e ficou lá. Meses, suponho que coisa de três meses. Nesse livro [Vespasiano, Meu Pai, de Nelly Martins]...

MH - Ela [Nelly Martins] fala disso no livro, mas...

WBM - Mas não precisa data? Mas, me parece que foi menos de um ano. 
MH - Durante o Estado Novo estava abafada a participação política dele, mas a liderança dele chegou a ser afetada, ou não, continuava sendo um grande líder...

WBM - Ele continuava sendo um líder. Tanto que ele foi, nessas eleições (1946) em que Dutra se elegeu, depois de Getúlio, ele foi candidato ao Senado e teve a maior votação de todos os candidatos, inclusive votação maior do que teve aqui no estado o candidato vitorioso a Presidência, o presidente Dutra. (...) Ele sempre ocupou aqui no estado uma posição de liderança, ora na oposição, ora na situação, mais na oposição do que na situação, porque ele se filiou a União Democrática Nacional e a UDN quase sempre militou na oposição.

MH - Pensando nesse espírito democrático, em que Getúlio chegou a governar, a gente percebe que a política aqui no estado, talvez pela presença do próprio Exército, é uma política mais ligada aos ideais democráticos do que ao coronelismo, como no nordeste. E é difícil você ver uma diferença entre uma geração política e outra. O senhor veio de uma geração política logo posterior a do Dr. Vespasiano. Qual era a diferença de geração? O que o Dr. Vespasiano pensava que o senhor pensava diferente?

WBM - Dr. Vespasiano pensava em ficar com os amigos dele, da geração anterior, que é o Filinto [Muller], o João Ponce, Villas-Boas... e pensava em ficar com o governo, com o Partido Social Democrático. Nós, a juventude, que formamos com antecipação à oposição aqui no estado, queríamos ficar na oposição ao governo Vargas. Puxamos o Vespasiano e ele veio conosco, até um pouco contrariado, mas veio conosco. Fechou conosco e ficou na UDN; chefe da UDN. Essa foi a verdade.

MH - Militaram na oposição a Vargas?

WBM - Na oposição a Filinto, ao Ponce, ao governo do Getúlio. A UDN foi oposicionista.

MH - E como projeto de país, ele apoiava a nacionalização do Getúlio Vargas às indústrias...

WBM - Ele era a favor, da legislação trabalhista também, mas tava sempre observando, pra ver se isso aí não extravasava a cultura e os interesses da sua própria região e dos seus companheiros. 
MH - Não era uma oposição fechada, não era contrária a Getúlio Vargas, mas contrária a alguma atitude dele.

WBM - É. Tanto que quando veio Getúlio aqui em certa ocasião... ele era Presidente. Vespasiano tava na oposição a Getúlio, e queriam aqui que ele assumisse a prefeitura. O governo do estado aqui era o Júlio Müller, queria que ele assumisse a prefeitura de Campo Grande e o próprio Getúlio insistiu pra que ele fosse Prefeito.

MH - Isso na época em que ele [o Governador] ainda nomeava os Prefeitos?

WBM - Sim. E Campo Grande tinha uma grande reivindicação nessa ocasião: era a construção do seu sistema de água, captação, adução, tratamento e distribuição de água para a cidade e havia um pleito do município pela concessão pela Caixa Econômica Federal de um empréstimo de dez milhões - na época era de reais - pra construção desse serviço de águas na cidade. Em nome desses projetos, desses interesses da cidade, ele aceitou ser Prefeito. Teve algum tempo na Prefeitura.

MH - E como foi a participação dele na formação dos partidos políticos aqui no estado [em 1946]?

WBM - Surgiram alguns partidos, aqui surgiram o... O partido que dava apoio ao oficialismo era o Partido Social Democrático; o maior partido da oposição era a UDN; o partido dos trabalhadores era o PTB, o Partido Trabalhista Brasileiro. Havia o partido do Adhemar de Barros, o PP... E também havia o partido do integralismo, o partido do Plínio Salgado, o Partido Integralista Brasileiro. E havia o Partido Socialista Brasileiro, o PSB. E esses são todos que havia na reconstitucionalização do país.

MH - E existiam diferenças ideológicas profundas, ou nem tanto?

WBM - Programaticamente, sim. Havia também o Partido Comunista Brasileiro, o PCB, que elegeu dois vereadores na Câmara Municipal [de Campo Grande]. Elegeram Artur de Barros e um outro que trabalhava n'O Democrata, aquele jornal comunista daqui, chamava Vasconcelos. Os dois eram comunistas.

BT - Esse período de 46 a 64, o senhor caracterizaria como um período de liberdades individuais, em que as pessoas podiam manifestar suas opiniões...

MH - Era um período de democracia plena? 
WBM - Nesse período houve democracia plena, houve eleição de Senadores comunistas. Mesmo o Luis Carlos Prestes foi Senador comunista, tinha uma bancada federal grande na Câmara dos Deputados, no Rio, até que veio a cassação desses mandatos e a prisão dos comunistas e sobreveio uma nova perseguição à esquerda. Como no período de Getúlio, foram presos Olga Benário Prestes - mulher do Luis Carlos Prestes, o Prestes, um jornalista alemão - que foi torturado na prisão - Harry Berger, foi preso um argentino, que também era famoso nas lutas na América do Sul [Rodolfo Ghioldi] e a Olga foi entregue pelo governo do Getúlio, com o Filinto, que era chefe de polícia no Rio, foi entregue à polícia de Hitler, e morreu nas câmaras de gás.

BT - Eu vou perguntar de novo sobre os militares, mas dessa vez é sobre todo esse período até 64. A gente sabe que o Mato Grosso antigo, ele era considerado - uma expressão do Euclides da Cunha - a "Sibéria canicular do funcionalismo público, civil e militar". Esses militares, em virtude deles darem problemas nos lugares de origem, eles vinham pra cá. E aqui, qual era a atuação deles na sociedade? Eles eram prezados pela sociedade? Eram hostilizados?

WBM - Os militares, eu me recordo, eu era mocinho, era rapazote, os militares aqui eram cotados, tinham boa cotação na sociedade, boa aceitação.

BT - Alguns filhos de comerciantes e agricultores iam estudar no Colégio Militar inclusive...

WBM - É verdade. Havia um bom trânsito pra eles. Nunca houve discriminação aqui com os militares.

BT - No movimento constitucionalista de 32, qual seria o suporte financeiro dos constitucionalistas, tanto aqui no antigo Mato Grosso, quanto em São Paulo. Quem financiou, quem ajudou a suprir as tropas, a máquina dos estados constitucionalistas?

WBM - Havia precariedade completa de recursos. Formavam-se os batalhões... Nós tivemos vários batalhões, meu pai mesmo foi comandante do batalhão que combateu na região de Três Lagoas, no Sucuriú e chegou até a Serra das Morangas, e que tinha o objetivo de impedir que as forças de Minas viessem, através de Paranaíba e Três Lagoas, e tomassem a [ferrovia] Noroeste. Havia precariedade completa de recursos. A chefia devia receber alguma coisa e repassar a esses comandantes de pelotões... Como é que nós chamávamos? Não eram 
pelotões, é de... colunas, e fazer [cobrir] as suas outras despesas, mas havia escassez completa de recursos. Posteriormente à nossa derrota, houve recebimento por parte de alguns dos chefes revolucionários de indenização de despesas que foram comprovadas; processo que se instaurou em São Paulo, e alguns receberam alguma coisa.

MH - Em São Paulo, há registros de pessoas que doavam brincos de ouro...

WBM - É, aqui também. Aqui se fazia isso.

BT - O envolvimento da população, aqui [Campo Grande]...

WBM - É... uma população pequena e pobre, então o que amealhavam, o que reuniam não era expressivo, era pouca coisa, mas houve esse movimento. De alianças, de jóias... "Ouro pelo bem de São Paulo, ouro pelo bem do Brasill".

MH - Insistindo um pouco nesse ponto da Revolução, a sede do governo ficava ali na [rua] Calógeras, naquele prédio da Maçonaria? Por que escolheram justamente aquele prédio da Maçonaria?

WBM - Não tenho conhecimento das razões que levaram... Primeiro, era um prédio central...

MH - Era um dos únicos que havia naquela época?

WBM - Aquela área da Afonso Pena e da Calógeras, com exceção da Prefeitura e do Rádio Clube, logo depois, e do Jornal do Comércio, eram casas residenciais. A Loja Maçônica era um prédio amplo, um espaço maior, e não tinha, também, necessidade de se reunir amiúde, com freqüência, então cedeu o prédio, certamente foi requisitado.

BT - A respeito da participação dos nortistas... Houve adesão do norte?

WBM - No norte não. O norte ficou todo com o norte.

BT - Então foi um racha mesmo?

WBM - Foi um racha. De Coxim pra baixo era nosso. Coxim mesmo ficou com o norte.

BT - Então o movimento de 32 foi um precursor do seccionismo, dos sulistas em relação ao norte...

MH - Esse já era um desejo velho, já... 
WBM - É, os limites da área que nós dominávamos, pelos projetos, aqui no sul, iam até o Taquari, compreendia Coxim. Eram mais ou menos esses limites do estado atual. O sul era isso.

MH - Os industriais de São Paulo apoiaram a Revolução. Aqui, qual era a posição das pessoas que apoiaram a Revolução... ou não houve discórdia nenhuma? WBM - Aqui, massivamente, todos apoiavam a Revolução. Havia certamente quem não apoiasse, mas não levantava a cabeça.

MH - Não houve nenhuma resistência... Talvez não apoiasse, mas também ficou calado...

WBM - Não me recordo de "Fulano não apóia"; o sujeito fugia, ia embora, não ia ficar aqui pra apanhar.

BT - Tinha o Silvino Jaques, lá na fronteira com o Paraguai...

WBM - Tinha o Silvino Jaques...

BT- Que era afilhado do Dr. Getúlio...

WBM - Era. Morava lá no município de Caracol. Naquela época não era município de Caracol, era município de Bela Vista, e Caracol era distrito de Bela Vista, foi emancipado posteriormente; mas lá era a casa dele... Eu conheci a casa dele há algum tempo.

BT - Mas esse também era meio que fugido, quando a barra pesava pro lado dele, ele pegava e fugia lá pro outro lado, do Paraguai.

WBM - (Risos).

MH - Eu não tenho mais perguntas. Bruno?

BT - (Negativa).

MH - A gente agradece, então. O senhor tem mais alguma coisa a dizer?

WBM - Acho que pude transmitir a vocês o pouco que sei. 